\title{
Pulsed dye Lazer Tedavisi Uygulanan Bir Lenfanjioma Sirkumskriptum Olgusu
}

\section{A Case of Lymphangioma Circumscriptum Treated with Pulsed Dye Laser}

\section{Turna İlknur, Sevgi Akarsu, Mehtap Ünlü Bıçak, Erdener Özer*, Emel Fetil}

Dokuz Eylül Üniversitesi Tıp Fakültesi, Deri ve Zührevi Hastalıklar Anabilim Dalı ve *Patoloji Anabilim Dalı, İzmir, Türkiye

\section{Özet}

Lenfanjioma sirkumskriptum (LS) genișlemiș dermal lenfatik damarlardan olușan yüzeyel bir vaskular malformasyondur. Klinik olarak içeriğinde genellikle berrak lenf sıvısı bulunmakla birlikte bazen hemorajiye bağlı olarak kırmızı kan hücrelerini de içeren gruplașmıș translusan veziküller izlenebilir. Vasküler lezyonlarda etkili olduğu bilinen pulsed dye lazer (PDL)'in bu tip hemorajik özellik gösteren lenfanjiomlarda da bașarılı olarak kullanılabileceği ileri sürülmüștür. Literatürde PDL tedavisi uygulanan ve lezyonları büyük oranda gerileyen LS'lu iki olgu bildirilmiștir. Burada sol omzunda bazıları hemorajik karakterde kabarcıkları olan ve PDL tedavisine yetersiz kısmi yanıt veren LS'lu 14 yașında bir kız olgu sunulmaktadır. (Türkderm 2012; 46: 107-9)

Anahtar Kelimeler: Lenfanjioma sirkumskriptum, pulsed dye lazer

\section{Summary}

Lymphangioma circumscriptum (LS) is a superficial lymphatic malformation which consists of dilated lymphatic channels. Clinically, it presents as grouped translucent vesicles, which usually contain clear lymph fluid but may also contain red blood cells due to hemorrhage. It has been suggested that pulsed dye laser (PDL), which efficacy is known in vascular lesions, has also been successfully used for such lympangiomas with hemorrhagic character. In the literature, two patients who had LS and whose lesions responded well to PDL treatment have been reported. Here, we describe a 14-year-old woman with LS who had vesicles on her left shoulder some of which showed hemorrhagic character and who gave an inadequate partial response to the treatment with PDL. (Turkderm 2012; 46: 107-9) Key Words: Lymphangioma circumscriptum, pulsed dye laser

\section{Giriş}

Lenfanjioma sirkumskriptum (LS) veya mikrokistik lenfatik malformasyon deri ve subkutanöz dokuları tutan nadir görülen bir vasküler malformasyondur. Tipik olarak 2-4 mm çapındaki vezikül kümecikleri berrak renkte olabileceği gibi lenfatik kanallar içindeki kan miktarına bağlı olarak pembe, kırmızı veya siyah renkte de görülebilir. Dermal papillalar üzerinde yerleşimli lenfatik damarlar epidermisi yukarı doğru iterek kesecikler şeklinde görünen veziküllerin oluşumuna neden olur. Genellikle ekstremitelerin proksimal kısımları, omuzlar, aksillar kıvrımlar, boyun ve özellikle dil olmak üzere oral kavitede yerleşen lezyonlar, penis, vulva ve skrotumda da görülebilmektedir 1,2 .
LS'da sayısı ve çapı zamanla artmaya eğilimli olan veziküller bazen rüptüre olarak kanamaya veya sızıntıya yol açabilir. Olgular genellikle sulantı, kabuklanma, ödem, kaşıntı ve sekonder infeksiyon oluşumundan rahatsızdırlar1,3. LS tedavisinde cerrahi, skleroterapi, kriyoterapi, ablatif ve ablatif olmayan lazerler gibi değişik tedavi seçeneklerinden bazı olgularda güzel sonuçlar alınmakla birlikte, lezyonların derin yerleşiminden dolayı nükslerin sık olduğu bildirilmiştir ${ }^{1-4}$. Noninvaziv bir yöntem olan pulsed dye lazer (PDL) tedavisi ile hemorajik lezyonları olan lenfanjiomlu olgularda belirgin başarı sağlandığı bildirilmiştir3,4. Burada PDL tedavisi uygulanan ve yetersiz kısmi yanıt alınan LS'lu bir olgu sunulmaktadır. 


\section{Olgu}

Sol omuzundaki kızarık kabarcıklar yakınması ile başvuran 14 yaşındaki kız olgu bu lezyonlarının doğumdan altı ay sonra oluştuğunu, zamanla büyüklüklerinin ve sayılarının arttığını tanımlamışıır. Bu yakınmalarına herhangi bir semptomun eşlik etmediğini ifade eden hastanın özgeçmiş, soygeçmiş ve sistem sorgulamasında herhangi bir özellik belirlenmemiştir. Olgumuzun dermatolojik muayenesinde boyunun sol yanından sol omuza doğru uzanım gösteren 1-4 mm çaplarındaki gruplaşmaya eğilimli renkleri açık pembeden koyu kırmızıya kadar değişen vezikül benzeri lezyonlar izlenmiştir (Resim 1a). Lezyonun histopatolojik incelemesinde yüzeyel dermiste kavernöz özellikte endotel hücreleri ile döşeli vasküler boşluklarda proteinöz bir materyal ve çevrede yoğun lenfoplazmositer bir infiltrasyon saptanmıştır (Resim 2).

Klinik ve histopatolojik bulgular eşliğinde LS tanısı konulan olgumuza bazı lezyonların hemorajik özellikte olmasından dolayı PDL tedavisi planlanmışır. Hasta 350 mikrosaniye atım süreli $585 \mathrm{~nm}$ dalga boylu PDL lazer (Nlite V, ICN Photonics Ltd, Wales, UK) ile $5 \mathrm{~mm}$ başlık çapı kullanılarak bitişik fakat örtüşmeyen atışlar yapılarak tedavi edilmiştir. Lazer tedavisi $6 \mathrm{~J} / \mathrm{cm}^{2}$ şeklinde başlanmış, 6-8 haftalık seans aralıklarında her seansta 0,5-1 J/ $\mathrm{cm}^{2}$ lik artışlar yapılarak maksimum 9 $\mathrm{J} / \mathrm{cm}^{2}$ dozunda 6 seans şeklinde uygulanmıştır. Lazer tedavisi seyrinde herhangi bir yan etkiye rastlanmamış olsa da, sadece hemorajik lezyonlarda kısmi gerileme izlenmiş ve bu yanıt yetersiz kısmi cevap olarak değerlendirilmiştir (Resim 1b).

\section{Tartışma}

Deri ve subkutanöz dokuları tutabilen lenfanjiomlar lenfatik sistemin hamartamatöz konjenital malformasyonlarıdır. LS ilk olarak 1877 yılında Wegener tarafından basit, kavernöz ve kistik olarak ayrılan lenfanjiom sınıflamasında basit grup altında incelenmiştir. Daha sonra anormal lenf damarlarının derinlik ve büyüklüklerine göre yüzeyel ve derin olarak sınıflandırılan lenfanjiomların yüzeyel alt grubu içinde yer almışıı ${ }^{1}$. Son olarak 1996 yılında Uluslararası Vaskuler Anomaliler Çalışma Derneği'nin sınıflamasında lenfanjiom olarak da bilinen konjenital lokalize lenfatik malformasyonların makrokistik (derin) ve mikrokistik (yüzeyel) formlara ayrıldığı, yüzeyel olan mikrokistik formun LS olarak da adlandırıldığı bildirilmiştir2.

LS patogenezi ilk olarak 1976 yılında Whimster ve arkadaşları tarafından tanımlanmıştır. Bu hipoteze göre embriyonik gelişim sırasında derin subkutanöz doku içinde normal lenf damarlarından ayrı olarak anormal lenfatik kesecikler oluşur. Ektopik lenf damarları ile bağlantılı olan bu kesecikleri çevreleyen düz kasların kasılması anormal ektopik lenf damarlarının dilatasyonuna ve deriden çıkıntı oluşturmasına neden olmaktadır1,2.

Klinik olarak doğumda veya doğumdan hemen sonra görülen, ancak herhangi bir yaşta da oluşabilen az sayıda gruplaşmaya eğilimli translusan
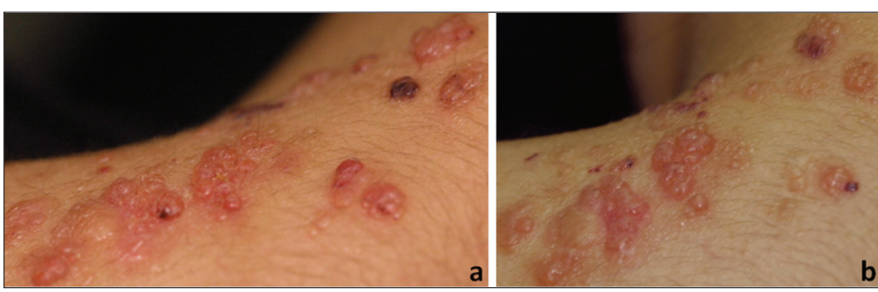

Resim 1. Lenfanjioma sirkumskriptum kliniğine uyan hemorajik veziküller (a), pulsed dye lazer tedavisi ile yetersiz kısmi yanıt (b) veziküller ile karakterizedir. LS'un klinik görünümleri birbirine benzemekle birlikte lezyonların büyüklükleri, dağılımı, histolojisi ve ilişkili semptomları birbirinden farklılık gösteren klasik ve lokalize formları tanımlanmıştır. Bizim olgumuzda da izlenen klasik form doğumda veya hemen sonrasında görülen, çapı bir santimetrekareden daha büyük olan, bazen veziküllerin görülmesinden önce diffüz palpabl subkutanöz bir şişlik fark edilebilen ve kalın verrüköz plakların çok nadir geliştiği formdur. Özellikle kol üst kısmı, aksilla, göğüs üst kısmı ve skapular alanlarda olmak üzere genellikle ekstremitelerin proksimal kısımlarında görülmektedir. Lokalize form ise çapı bir santimetrekareden küçük olan, genellikle erişkinlerde olmak üzere herhangi bir yaşta ve vücudun herhangi bir yerinde görülebilen lezyonlarla karakterizedir. Bununla birlikte her iki formun birlikte görülebildiği olgular da bildirilmiştir? .

LS ayırıcı tanısında lenfanjiektaziler, kutan metastazlar, hemanjiom, verruka, molloskum kontagiozum, anjiokeratom ve lenfanjioendoteliyom gibi tablolar düşünülmelidir'. Ayırıcı tanı için yapılan histopatolojik incelemede papillar dermisteki çok fazla sayıda genişlemiş kalın duvarlı lenfatik kanalların sıklıkla retiküler dermis ve subkutanöz dokuya kadar uzandığı görülür1,2. Etkilenmiş olan damarların lümeni lenfatik sıvı ve sıklıkla kırmızı ve beyaz kan hücreleri ile doludur. Genişlemiş lenfatiklerin içine kırmızı kan hücrelerinin ekstravazasyonunun mekanizması net olarak bilinmemekle birlikte, kapillerler ve küçük lenfatikler arasındaki çok küçük kanalların rolü olabileceği ileri sürülmüştür 1,5. Ayrıca dermiste yoğun lenfosit infiltrasyonu ve fibroplazi görülmektedir?

Tedavideki temel hedefler kozmetik kaygılara ek olarak devamlı lenfatik ve kan sızıntısı, ağrı, ödem ve persistan süperinfeksiyonlara yönelik olmalıdır3,4. Lenfanjiomların primer tedavisi için tercih edilen yaklaşım cerrahi eksizyondur. En düşük nüks oranlarının cerrahi ile olduğu bildirilmekle birlikte her hastada uygulanamayan ve sikatris bırakan bir yöntemdir2-4. Cerrahi dışındaki diğer tedavi seçenekleri arasında skleroterapi, radyoterapi, X ışınları, kriyoterapi, koterizasyon, radyofrekans enerjisi ve bazı lazerler bulunmaktadır,6. Bu tedavi yaklaşımların birçoğundan derin komponentlere ulaşımdaki yetersizliği ve multifokal lezyonlara bağlı yüksek nüks oranları nedeniyle yüz güldürücü sonuçlar alınamamaktadır ${ }^{3}$.

LS tedavisinde ablatif ve ablatif olmayan pek çok lazer kullanılmış olup her biri için değişik başarı oranları bildirilmiştir 7-15. Lenfanjiomların tedavisinde genellikle yüzeydeki lenfatik damarları nonspesifik olarak buharlaştıran ve

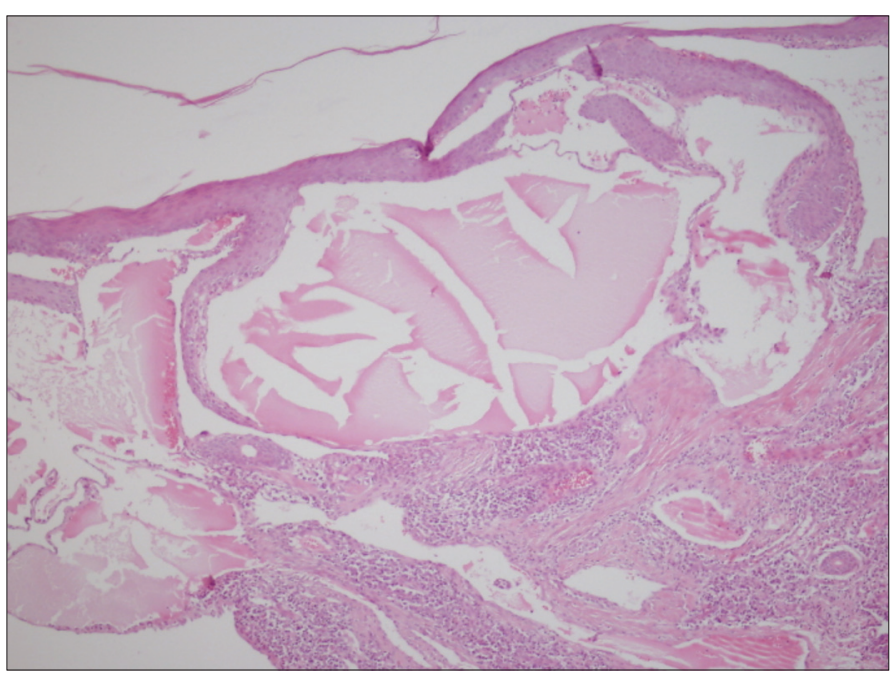

Resim 2. Yüzeyel dermiste içi seröz sıvı ile dolu kavernöz yapılar ve anjiomatöz yapıların çevresinde yoğun lenfositten baskın mononükleer infiltrat (H\&E x100) 
derindeki yapılarla bağlantılı lenfatik kanalları kapatan karbondioksit lazerden başarılı sonuçlar alınmıştır. Ancak karbondioksit lazer gibi ablatif lazerlerin lokal veya genel anestezi gerektirmesi ve belirgin sikatris bırakması gibi dezavantajları bulunmaktadır8,9.

Vasküler lezyonların tedavisinde kullanılan PDL'ler vasküler dokuların termal gevşeme zamanlarına en uygun atımlar üreten ve bu nedenle de bu amaçla kullanılan lazerler içinde sikatris ya da pigmentasyon bozukluğu oluşturma riski en az olan lazerlerdir. Selektif fototermoliz mekanizması ile çevredeki dokuya zarar vermeden selektif vasküler hasara neden olan bu lazer sistemi nevus flammeus, telenjiektazi ve hemanjiom gibi vasküler lezyonlara ek olarak verruka ve keloid gibi damarsal komponenti olan değişik lezyonlarda da kullanılmaktadır16,17. Her ne kadar başlangıçta ancak papiller dermiste vasküler hasar yaratabilen $577 \mathrm{~nm}$ dalga boyu kullanılsa da, sonra bu dalga boyu $585 \mathrm{~nm}$ olarak modifiye edilerek 1,2 mm derinlikte vasküler hasara olanak sağlanmıştır. Her iki dalga boyu da 330 450 s atım süresiyle yüzeyel kan damarlarında spesifik hasar oluşumuna olanak vermektedirler ${ }^{18}$. PDL'in yüzeyel penetrasyon derinliği ve berrak lenfatik veziküllerde kromofor görevi gören oksihemoglobinin olmaması PDL ile LS tedavisinde soru işaretleri oluştursa da, literatürde hemorajik lenfatik lezyonlarda etkili olarak kullanılabileceği bildirilmiştir 10,11,15. Literatürde 577 nm ve 585 nm dalga boylu PDL uygulanan LS'lu iki olguda da başarılı yanıt alındığı, ancak bir olguda üç yıl sonrasında nüks izlendiği gözlenmiş̧ir 10,11. Yine dil üzerinde hemorajik lenfatik malformasyonu olan bir olguda $595 \mathrm{~nm}$ dalga boylu PDL tedavisi ile tama yakın gerileme ile birlikte 10 aylık izlem süresince nüks izlenmediği bildirilmiştir ${ }^{15}$. Lezyonun yerleşim yeri, derinliği, veziküler yapıların hemorajik içeriği gibi pek çok parametre lazer tedavilerinin başarı şansını etkiliyor olsa da, bizim olgumuzda ki yetersiz kısmi yanıt PDL'in hemorajik özellikte dahi olsa her LS'lu olguda etkili olamayabileceğini göstermektedir.

\section{Kaynaklar}

1. Patel GA, Schwartz RA: Cutaneous lymphangioma circumscriptum: frog spawn on the skin. Int J Dermatol 2009;48:1290-5.

2. Garzon MC, Huang JT, Enjolras O, Frieden IJ: Vascular malformations: Part I. J Am Acad Dermatol 2007;56:353-70; quiz 371-4.
3. Bond J, Basheer MH, Gordon D: Lymphangioma circumscriptum: pitfalls and problems in definitive management. Dermatol Surg 2008;34:271-5.

4. Greene AK, Perlyn CA, Alomari Al: Management of lymphatic malformations. Clin Plast Surg 2011;38:75-82.

5. Arpaia N, Cassano N, Vena GA: Dermoscopic features of cutaneous lymphangioma circumscriptum. Dermatol Surg 2006;32:852-4.

6. Niti K, Manish P: Microcystic lymphatic malformation (lymphangioma circumscriptum) treated using a minimally invasive technique of radiofrequency ablation and sclerotherapy. Dermatol Surg 2010;36:1711-7.

7. Landthaler M, Haina D, Waidelich W, Braun-Falco O: [Treatment of circumscribed lymphangiomas with the argon laser]. Hautarzt 1982;33:266-70.

8. Haas $A F$, Narurkar VA: Recalcitrant breast lymphangioma circumscriptum treated by UltraPulse carbon dioxide laser. Dermatol Surg 1998;24:893-5.

9. Treharne LJ, Murison MS: CO2 laser ablation of lymphangioma circumscriptum of the scrotum. Lymphat Res Biol 2006;4:101-3.

10. Weingold $D H$, White $P F$, Burton CS: Treatment of lymphangioma circumscriptum with tunable dye laser. Cutis 1990;45:365-6.

11. Lai CH, Hanson SG, Mallory SB: Lymphangioma circumscriptum treated with pulsed dye laser. Pediatr Dermatol 2001;18:509-10.

12. Lapidoth M, Ackerman L, Amitai DB, Raveh E, Kalish E, David M: Treatment of lymphangioma circumscriptum with combined radiofrequency current and $900 \mathrm{~nm}$ diode laser. Dermatol Surg 2006;32:790-4.

13. Thissen CA, Sommer A: Treatment of lymphangioma circumscriptum with the intense pulsed light system. Int J Dermatol 2007;46:16-8.

14. Demir E, Isen K, Büyükbayram H: Lymphangioma circumscriptum of the glans penis treated with advanced fluorescence technology pulsed light therapy: case report (Advanced fluorescence technology pulsed light ile tedavi edilen glans penis lenfanjioma sirkumskriptumu). Turkiye Klinikleri J Med Sci 2010;30:1417-20.

15. Wang LC, Krunic AL, Medenica MM, Soltani K, Busbey S: Treatment of hemorrhagic lymphatic malformation of the tongue with a pulsed-dye laser. J Am Acad Dermatol 2005;52:1088-90.

16. Railan D, Parlette EC, Uebelhoer NS, Rohrer TE: Laser treatment of vascular lesions. Clin Dermatol 2006;24:8-15.

17. Barčot Z, Zupančić B: Pulsed dye laser treatment of vascular lesions in childhood. Acta Dermatovenerol Croat 2010;18:201-8.

18. Geronemus RG: Pulsed dye laser treatment of vascular lesions in children. J Dermatol Surg Oncol 1993;19:303-10. 